\title{
Socialization and Training at Gloria Muda Volleyball Club
}

\author{
Edi Irwanto1, Danang Ari Santoso², Bayu Septa M.T33, Marki Sandi4, Dadang Mubin ${ }^{5}$ \\ 1,2,3,4,5 PGRI Banyuwangi University \\ Email: 1irwantoedi88@gmail.com, 2danangarisantoso@gmail.com,3bayusepta7@gmail.com, \\ 4markysandy22@gmail.com, dadangshafa@gmail.com

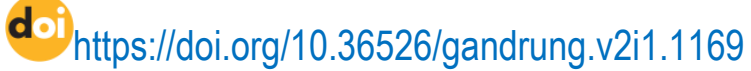

\begin{abstract}
The purpose of this service is to provide socialization and training at Gloria Muda Tambakrejo volleyball club, Bulurejo Village, Purwoharjo District, Banyuwangi Regency. The method used in this service is discussion and direct training (demonstration and practice) to the coaches and volleyball players of Gloria Muda Tambakrejo. The result of this activity was that the volleyball club coach Gloria Muda Tambakrejo gained new insights regarding the training program and how to train and was able to develop a training program that could be used to develop the technique and game of the Tambakrejo volleyball club. Young Gloria club players get training programmed according to the training program that suits their needs. Increased basic technical skills of passing, smash and vertical jump height of club players Gloria Muda Tambakrejo. Increased skills of passing and smash techniques and physical conditions (vertical jump) by $6.17 \%$. For the basic technique of passing, there was an increase of $9,53 \%$. For the basic smash technique there is an increase of $3.20 \%$. For the ability to vertical jump there is an increase of $3,87 \%$.
\end{abstract}

Keyword: Socialization, Training, Volleyball

\section{Pendahuluan}

Bolavoli adalah permainan yang dilakukan oleh dua regu, yang masing-masing terdiri dari enam orang atlet yang dipisahkan sebuah net di tengah lapangan. Hal ini sebagaimana yang dikemukakan oleh Akhbar (2020), bolavoli merupakan salah cabang permainan bola besar yang dimainkan oleh dua tim yang saling berlawanan di dalam sebuah lapangan dan dibatasi oleh net antara tim. Seperti oahraga lainya bolavoli terdiri dari beberapa teknik dasar yang harus dikuasai diantara adalah passing, smash dan bendungan.

Passing pada dasarnya merupakan kunci dalam suatu permainan bolavoli maka passing mutlak untuk dikuasai oleh semua atlet. Bentuk latihan biasanya diberikan untuk meningkatkan kemampuan teknik dasar passing bawah permainan bolavoli yaitu passing bawah dengan berpasangan. Agar mampu melakukan passing bawah dengan baik dan benar harus dilakukan latihan yang sistematis dan terprogram. Seorang pelatih harus mampu memilih metode latihan yang mudah dipelajari dan dipahami, salah satunya dengan menggunakan metode dalam bentuk latihan. Bentuk latihan yang akan diberikan untuk meningkatkan kemampuan teknik dasar passing bawah permainan bolavoli yaitu passing bawah dengan berpasangan (Sarwita, 2017). Selain passing teknik selajutnya yang paling berpengaruh adalah 
GANDRUNG: Jurnal Pengabdian Kepada Masyarakat ISSN: 2721-6136 (Online)

teknik dasar smash.

Smash adalah suatu teknik dasar permainan bolavoli yang dilakukan dengan memukul bola untuk mendapatkan point. Hal ini sebagaimana yang dikemukakan oleh Winarno et all (2013), Teknik Smash adalah cara memainkan bola dengan efisien dan efektif sesuai dengan peraturan permainan untuk mencapai smash keras yang bertujuan mematikan permainan lawan sehingga dapat menghasilkan point. Dalam melakukan pada permainan bolavoli tidak hanya keras dan tajamnya hasil smash, hal lain yang perlu diperhatikan dalam melakukan teknik smash adalah tinggi lompatan vertical jump.

Tinggi lompatan vertical jump adalah suatu kemampuan fisik yang terfokus pada otot tungkai seorang atlit pada saat melakukan lompatan ke atas atau vertical. Dalam permainan bolavoli tinggi loncatan merupakan faktor pendukung dalam melakukan smash. Oleh karena itu, atlet bolavoli harus memiliki loncatan yang tinggi. "Salah satu fitur kondisional yang paling penting dan spesifik untuk bolavoli adalah loncatan" (Cimenli et all., 2016). Untuk memiliki kemampuan atau prestasi bermain bolavoli yang bagus, setiap atlet atau individu harus memiliki keterampilan keseluruahan teknik dasar mulai dari servis, passing, smash dan bendungan yang bagus. Agar memiliki kemampuan teknik dasar yang bagus maka diperlukan kedisiplinan dan keseriusan dalam melakukann latihan.

Latihan merupakan proses sistematis menggunakan gerakan bertujuan meningkatkan atau mempertahankan kualitas fungsi tubuh yang meliputi kualitas daya tahan paru-jantung, kekuatan dan daya tahan otot, kelentukan dan komposisi tubuh (Irianto, 2004). Latihan yang baik harus memiliki program latihan yang disesuaikan dengan kebutuhan atlit atau tim. Program latihan adalah suatu rencana jangka panjang atau pendek yang digunakan oleh pelatih untuk menentukan jadwal dan jenis latihan yang dilaksanakan. Seiring berjalanya waktu, permainan bolavoli sudah mengalami kemajuan dari berbagai bidang bolavoli dan mengikuti perkembangan zaman. Tujuan pengembangan permainan bolavoli salah satu sasarannya adalah untuk meningkatkan prestasi di klub atau pada atlet yang berbakat, dilihat dari proses latihan secara kontinue yang memiliki program terpadu (Wahyudi \& Donie, 2019).

Melihat tren dalam bolavoli dari segi teknik, terbukti bahwa smash yang kuat oleh atlet menjadi penunjang untuk menghasilkan point (Kumar, et all., 2016). Untuk menunjang kemampuan smash yang baik dibutuhkan kondisi fisik, yaitu kekuatan dan daya ledak (Wismiarti \& Hermanzony, 2020). Untuk dapat mengoptimalkan smash dibutuhkan umpan bola yang baik dari set upper, supaya set upper dapat memberikan umpan dengan baik dibutuhhkan bola hasil passing yang baik sesuai dengan kebutuhan set upper. Untuk mendapatkan koordinasasi tersebut perlu dilakukan latihan. Prestasi seorang atlet sangat ditentukan oleh kualitas pelatih dan progam latihannya, sehingga didirikanlah klub sebagai wadah 
GANDRUNG: Jurnal Pengabdian Kepada Masyarakat ISSN: 2721-6136 (Online)

pelatihan dan pembinaan atlet (Ma'mun \& Subroto, 2000). Peran pembinaan olahraga harus diprogramkan secara optimal, untuk mengorganisasi jalannya pembinaan sesuai dengan program yang telah disusun secara sistematis. Menurut pendapat Bompa dan Haff (2009) "Faktor penting bagi pengembangan system latihan dapat berasal dari pengetahuan umum tentang teori dan metode latihan, temuan-temuan ilmiah, pengalaman dari pelatih terbaik bangsa, dan pendekatan yang digunakan oleh negara-negara lain".

Sehingga dari uraian diatas perlu adanya sosialisasi terkait program latihan pada club bolavoli dan pemberian latihan teknik dasar bolavoli kepada atlet di daerah-daerah yang kurang berkembang, salah satunya di club bolavoli Gloria Muda Tambakrejo. Sosialisasi yang diberikan berupa pemahaman dan menyusun program latihan. Supaya pelatih mampu meyusun program latihan. Latihan yang diberikan berupa latihan teknik dasar passing bawah, smash dan vertical jump. Hal ini dikarenakan ketiga latihan tersebut diatas merupakan bagian dari teknik permainan bolavoli yang sangat mempengaruhi kemampuan bermain bolavoli.

Dari hasil observasi yang dilakukan pada club bolavoli Gloria Muda Tambakrejo desa Bulurejo Kecamatan Purwoharjo, diketahui bahwa club tersebut tidak memiliki pelatih yang berlisensi, ada seseorang yang di anggap mampu dan mantan atlet di era 90an. Latihan dilakukan tidak terjadwal, tidak memiliki program latihan.

Dari urian diatas maka tertuang gagasan penulis untuk melakukan kegiatan pengabdian kepada masyarakat (PKM) dengan judul Sosialisasi dan pelatihan pada club bolavoli Gloria Muda Tambakrejo Desa Bulurejo Kecematan Purwoharjo Kabupaten Banyuwangi. Diharapkan dengan adanya kegiatan ini dapat membantu mengatasi permasalahan club Gloria Muda.

\section{Metode}

Metode yang digunakan pada pengabdian kepada masyarakat ini adalah community development practice, yaitu memberikan pemahaman kepada sekelompok masyarakat (pembina dan atlet bolavoli Gloria Muda). Adapun tahapan pengabdian kepada masyarakat ini antara lain:

\section{Persiapan}

Tahapan persiapan meliputi observasi, diskusi dengan pembina club bolavoli Gloria Muda, dan penyusunan program latihan. 
GANDRUNG: Jurnal Pengabdian Kepada Masyarakat ISSN: 2721-6136 (Online)

\section{Pelaksanaan}

a. Kegiatan dilaksanakan mulai tanggal $02-24$ Januari 2021

b. Diskusi dan pemberian pemahaman terkait program latihan kepada Pembina dan para atlet pada tanggal 2-3 januari 2021.

c. Memberikan pelatihan keterampilan teknik dasar passing, smash, dan vertical jump. Pelaksanaan latihan dilakukan selama Sembilan kali tatap muka selam tanggal 4-23 januari 2021.

3. Evaluasi

Diadakan pree test untuk data awal dan posttest untuk mengetahui hasil dari latihan yang sudah dilaksanakan

\section{Hasil dan Diskusi}

Dari hasil diskusi dengan pembina dan para atlet serta pengamatan, maka disusunlah program latihan sesuai dengan kebutuhan club Gloria Muda yaitu latihan passing, latihan smash, dan kondisi fisik (tinggi lompatan) tersaji pada gambar 1 dibawah ini. .
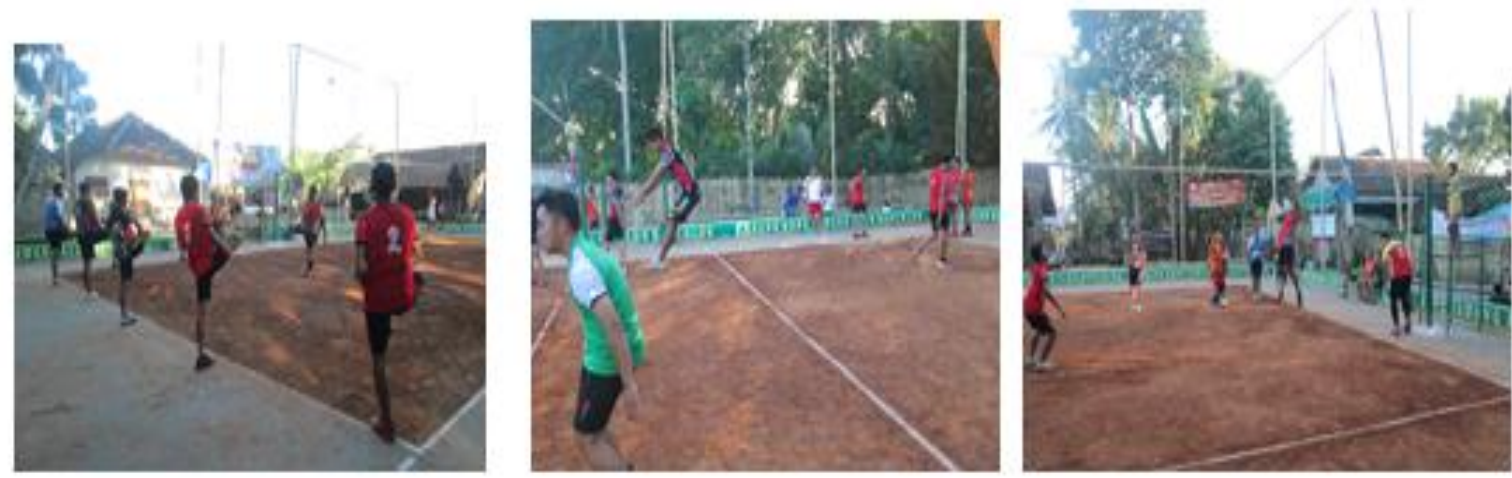

Gambar 1. Proses Latihan

Selanjutnya dilakukan pengambilan data pree test sebagai acuan awal. Pree test dilaksanakan pada tanggal 3 Januari 2021. Pengambilan data Passing Bawah menggunakan AAPHER Test, Smash menggunakan Batery Test dan tinggi lompatan menggunakan mistar ukur. Hasil pree test tersaji pada tabel 1 berikut:

Tabel 1. Data Pree Test Atlet Club Gloria Muda.

\begin{tabular}{cccc}
\hline $\mathrm{N}$ & Passing bawah & Smash & Tinggi lompatan \\
\hline 14 & 42,714 & 28 & 49,642 \\
\hline
\end{tabular}

Kemudian dilaksanakan pelatihan sesuai dengan Program latihan dilakukan selama 9 kali 
GANDRUNG: Jurnal Pengabdian Kepada Masyarakat ISSN: 2721-6136 (Online)

pertemuan, dengan frekwensi 3 kali dalam satu minggu (senin, selasa dan sabtu). Berikut program latihan yang digunakan tersaji pada tabel 2,3, dan 4 dibawah ini:

Tabel 2. Program Latihan Pertemuan 1 - 3

\begin{tabular}{|c|c|c|c|}
\hline HARI & Senin $(4 / 1 / 21)$ & $\operatorname{Rabu}(6 / 1 / 21)$ & Sabtu $(9 / 1 / 21)$ \\
\hline 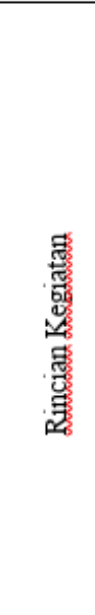 & $\begin{array}{l}\text { 1. Lari } 3 X \text { putaran } \\
\text { 2. Stratching \& Koord } \\
\text { 3. Speed: } \\
\text { TOSSER } \\
\text { - } 4 \times 50 \text { Jump toss } \\
\text { (passing atas) } \\
\text { (Rest: } 10-15^{\circ} \text { ) } \\
\text { SMASH (open spiker) } \\
\text {-4x } 75 \text { Smash open } \\
\text { (Rest: } 10-15^{\circ} \text { ) } \\
\text { SMASH (quick spiker) } \\
\text { - } 4 \times 75 \text { Smash full } \\
\text { (Rest: } 10-15^{\circ} \text { ) } \\
\text { 4. Conditioning: } \\
\text { - Sit Up }=80 \text { kali } \\
\text { - Back Up }=60 \text { kali } \\
\text { 5. Joging } 1 \text { putaran } \\
\text { 6. Stratching }\end{array}$ & $\begin{array}{l}\text { 1. Lari } 3 X \text { putaran } \\
\text { 2. Stratching \& Koord } \\
\text { 3. W. Training (Beban): } \\
\text { - Squat } 10 \times 3 \\
\text { - Snact } 10 \times 3 \\
\text { - Split } 20 \times 3 \\
\text { - Leg ccrul \& } \\
\text { leg Exst } 3 \text { set } \\
\text { (Rest: } 3^{\circ} \text { ) } \\
\text { 4. Joging } 1 \text { putaran } \\
\text { 5. Stratching }\end{array}$ & $\begin{array}{l}\text { 1. Lari } 3 X \text { putaran } \\
\text { 2. Stabilisasi } \\
\text { 3. Koordinasi } \\
\text { 4. Pasing } \\
\text { - Latihan pasing } \\
\text { bawwah berpasangan } \\
(1-1,2-2) 10 \text { menit } \\
\text { - Latihan pasing atas } \\
\text { berpasangan (1-1, 2- } \\
\text { 2) } 10 \text { menit. } \\
\text { - Latihan Drill pasing } \\
\text { bawah dan pasing } \\
\text { atas } 10 \text { menit } \\
\text { 5. Latihan xariasi serangan } \\
\text { dan pertahanan } \\
\text { 6. Jogging } 1 \text { putaran } \\
\text { 7. Stratching }\end{array}$ \\
\hline 骂 & $\begin{array}{c}\text { Absolut } \\
50 \%\end{array}$ & Sesuai kebutuhan atlet & Kecepatan $55 \%$ \\
\hline
\end{tabular}

Tabel 3. Program Latihan Pertemuan 4- 6

\begin{tabular}{|c|c|c|c|}
\hline HARI & $\operatorname{Senin}(11 / 1 / 21)$ & $\operatorname{Rabu}(13 / 1 / 21)$ & Sabtu $(16 / 1 / 21)$ \\
\hline 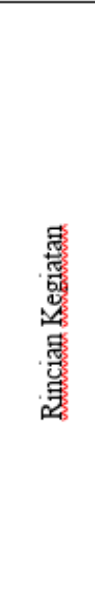 & $\begin{array}{l}\text { 1. Lari } 3 \mathrm{X} \text { putaran } \\
\text { 2. Stratching \& Koord } \\
\text { 3. Speed: } \\
\text { TOSSER } \\
\text { - } 6 \times 50 \text { Jump toss } \\
\text { (passing atas) } \\
\text { (Rest: } 20^{\circ} \text { ) } \\
\text { SMASH (open spiker) } \\
\text { - } 6 \times 75 \text { Smash open } \\
\text { (Rest }: 20^{\circ} \text { ) } \\
\text { SMASH (quick spiker) } \\
\text { - } 6 \times 75 \text { Smash full } \\
\text { (Rest: } 20^{\circ} \text { ) } \\
\text { 4. Conditioning: } \\
\text { - Sit Up }=80 \text { kali } \\
\text { - Back Up }=60 \text { kali } \\
\text { 5. Joging } 1 \text { putaran } \\
\text { 6. Stratching }\end{array}$ & $\begin{array}{l}\text { 1. Lari } 3 X \text { putaran } \\
\text { 2. Stratching \& Koord } \\
\text { 3. W. Training (Beban): } \\
\text { - Squat } 10 \times 3 \\
\text { - Snact } 10 \times 3 \\
\text { - Split } 20 \times 3 \\
\text { - Leg ccrul \& } \\
\text { leg Exst } 3 \text { set } \\
\text { (Rest: } 3^{\prime} \text { ) } \\
\text { 4. Joging } 1 \text { putaran } \\
\text { 5. Stratching }\end{array}$ & $\begin{array}{l}\text { 1. Lari } 3 X \text { putaran } \\
\text { 2. Stratching \& Koord } \\
\text { 3. Speed endurance: } \\
\text { TOSSER } \\
\text { - Lari }=6 \times 300 \mathrm{~m} \\
\text { (Rest: } 5^{\circ}-7^{\prime} \text { ) } \\
\text { SMASH (open spiker) } \\
\text { Lari }=3 \times 2 \times 600 \mathrm{M} \\
\text { (Rest: } 1,5-2 \text { menit) } \\
\text { SMASH (quick spiker) } \\
\text { Lari }=5 \times 2 \times 600 \mathrm{M} \\
\text { (Rest: } 5-8 \text { menit) } \\
\text { 4. Joging } 1 \text { putaran } \\
\text { 5. Stratching }\end{array}$ \\
\hline 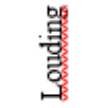 & $\begin{array}{c}\text { Absolut } \\
60 \%\end{array}$ & Sesuai kebutuhan atlet & Kecepatan $65 \%$ \\
\hline
\end{tabular}


GANDRUNG: Jurnal Pengabdian Kepada Masyarakat ISSN: 2721-6136 (Online)

Tabel 4. Program Latihan Pertemuan 7-9

\begin{tabular}{|c|c|c|c|}
\hline HARI & $\operatorname{Senin}(18 / 1 / 21)$ & Rabu $(20 / 1 / 21)$ & Sabtu 23/1/21) \\
\hline 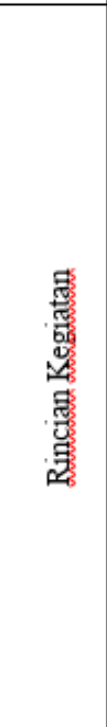 & $\begin{array}{l}\text { 1. Lari 3X putaran } \\
\text { 2. Stratching \& Koord } \\
\text { 3. Speed: } \\
\text { TOSSER } \\
\text { - } 1 \times 50 \text { Jump toss } \\
\text { (passing atas) } \\
\text { (Rest: } 20^{\circ} \text { ) } \\
\text { SMASH (open } \\
\text { spiker) } \\
\text { - } 1 \times 75 \text { Smash open } \\
\text { (Rest :20') } \\
\text { SMASH (quick } \\
\text { spiker) } \\
\text { - 1 x } 75 \text { Smash full } \\
\text { (Rest: } 20^{\circ} \text { ) } \\
\text { 4. Conditioning: } \\
\text { - Sit Up }=80 \text { kali } \\
\text { - Back Up = } 60 \text { kali } \\
\text { 5. Joging } 1 \text { putaran } \\
\text { 6. Stratching }\end{array}$ & $\begin{array}{l}\text { 1.Lari 3X putaran } \\
\text { 2.Stratching \& Koord } \\
\text { 3.W. Training } \\
\text { (Beban): } \\
\text { - Squat } 10 \times 3 \\
\text { - Snact } 10 \times 3 \\
\text { - Split } 20 \times 3 \\
\text { - Leg cctul \& } \\
\text { leg Exst } 3 \text { set } \\
\text { (Rest: } 3^{\prime} \text { ) } \\
\text { 4. Joging } 1 \text { putaran } \\
\text { 5.Stratching } \\
\text { Atau latihan tanding }\end{array}$ & $\begin{array}{l}\text { 1. Lari 3X putaran } \\
\text { 2. Stratching \& Koord } \\
\text { 3. Speed endurance: } \\
\text { TOSSER } \\
\text { - Lari }=1 \times 300 \mathrm{~m} \\
\text { (Rest: } 5^{\prime}-7^{\prime} \text { ) } \\
\text { SMASH (open spiker) } \\
\text { Lari }=1 \times 2 \times 600 \mathrm{M} \\
\text { (Rest: } 1,5-2 \text { menit) } \\
\text { SMASH (quick spiker) } \\
\text { Lari }=1 \times 2 \times 600 \mathrm{M} \\
\text { (Rest: } 5-8 \text { menit) } \\
\text { 4. Joging } 1 \text { putaran } \\
\text { 5. Stratching }\end{array}$ \\
\hline 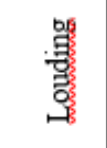 & $\begin{array}{c}\text { Absolut } \\
70 \%\end{array}$ & Sesuai kebutuhan atlet & $\begin{array}{r}\text { Kecepatan } 75 \% \\
\text { Activ }\end{array}$ \\
\hline
\end{tabular}

Setelah melakukan latihan selama 9 kali pertemuan dilakukan pengambilan data Post Test yang dilaksanakan pada tanggal 24 Januari 2021. Hasil post test tersaji pada tabel 4 berikut:

Tabel 4. Data Post Test Atlet Club Gloria Muda.

\begin{tabular}{cccc}
\hline $\mathrm{N}$ & Passing bawah & Smash & Tinggi lompatan \\
\hline 14 & 47,214 & 28,928 & 51,642 \\
\hline
\end{tabular}

Hasil pengambilan data Pree Test dan Post Test di atas dapat disajikan dalam bentuk grafik sebagai berikut.

\section{Data Pemain}

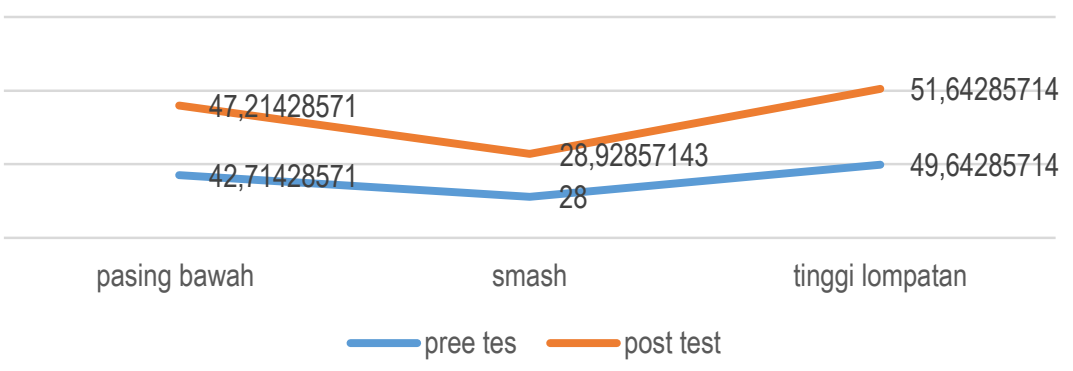

Gambar 2. Grafik Data Atlet 
Dari grafik diatas dapat diketahui secara rata-rata terdapat peningkatan keterampilan teknik passing dan smash serta kondsisi fisik (tinggi lompatan) sebesar 6,17\%. Untuk kemampuan teknik dasar passing terdapat peningkatan sebesar 9,53\%. Untuk kemampuan teknik dasar smash terdapat peningkatan sebesar 3, 20\%. Untuk kemampuan lompatan vertical jump terdapat peningkatan sebesar $3,87 \%$. Hal ini dikarenakan para atlet mendapatkan latihan drill, latihan berpasangan, latihan kondisi fisik yang terprogram sesuai jadwal latihan yang sudah dibuat. Hal ini sebagaimana dikemukakakan Irwanto (2017), yang menyatakan penggunaan metode latihan drill dapat meningkatkan keterampilan teknik dasar bolavoli. Hal senada juga dikemukakan oleh Defrizal dan Suharjana, (2019), yang menyatakan penerapan latihan drill tidak hanya sebagai upaya meningkatkan kemampuan penguasaan teknik passing bawah atlet bolavoli, melainkan memaksimalkan performa atlet dan keterampilan bolavoli secara holistic.

Hasil yang didapat juga dikarenakan para atlet bersemangat dan disiplin dalam mengikuti latihan. Sarwita (2017) menyatakan penguasaan teknik dasar secara sempurna dapat dicapai dengan melakukan latihan-latihan secara kontinyu dan mengunakan metode yang baik. Dalam permainan Bolavoli tentunya para atlet harus mempunyai kecakapan teknik dasar yang baik sehingga bisa mencapai prestasi yang diinginkan. Dan didukung oleh Akhbar MT. (2020) yang menyatakan untuk memiliki kecakapan khusus para atlet tidak terlepas dari latihan-latihan, baik itu latihan secara fisik maupun teknik.

Pelatihan dan sosialisasi yang dilakukan pada club bolavoli Gloria Muda Tambakrejo dapat dikatakan berhasil. Pemberian latihan mampu meningkatkan keterampilan atlet club Gloria Muda Muda Tambakrejo. Hal ini tidak lepas dari keaktifan dan kedisiplinan para atlet dalam mengikuti latihan dan juga dukungan penuh dari Pembina club bolavoli Gloria Muda. Dengan adanya kegiatan ini atlet merasa senang karena teknik dasar yang dimiliki semakin meningkat dan mendapatkan pengalaman serta wawasan bagaimana cara melakukan latihan teknik dasar bolavoli yang terprogram. Sahabudin dan Hakim (2020) menyatakan untuk mendapatkan keterampilan atau skill yang maksimal dibutuhkan program latihan dengan berbagai metode dan model latihan yang dilakukan secara sistematis dan terprogram, dan Adanya sosialisasi model latihan teknik dasar dalam permainan bolavoli sangat membantu untuk mencapai keterampilan teknik secara maksimal.

\section{Kesimpulan}

Dari kegiatan yang sudah dilaksanakan dapat disimpulkan bahwa pembina club bolavoli Gloria Muda tambakrejo memahami bagaimana menyusun program latihan bolavoli sesuai dengan kebutuhan untuk meningkatnya keterampilan teknik dasar bolavoli. Meningkatnya keterampilan bermain bolavoli 
GANDRUNG: Jurnal Pengabdian Kepada Masyarakat ISSN: 2721-6136 (Online)

diantaranya adalah passing, smash, dan tinggi lompatan. Perlu kiranya diberikan latihan strategi penyerangan dan pertahanan guna meningkatkan dan menambah wawasan serta kemampuan bertanding.

\section{Daftar Referensi}

Akhbar, M. T. (2020). Pengaruh Latihan Curl Dumble Terhadap Hasil Smash Bolavoli Siswa. Jurnal IImu Keolahragaan. Vol 3 No 1; 20-29

Bompa, T.O.\& Haff, G.G. (2009). Theory and Methodology of Training.Human Kinetics (Advantage).

Cimenli, O., et all. (2016). Effect of an Eight Week Plyometric Training on Different Surfaces on The Jumping Performance of Male Volleyball Players. Journal of Physical Education and Sport. Vol 16 No $1 ; 162-169$

Defrizal, D. \& Suharjana, S. (2019). Drill Training as Effective Methods on Increasing Under Passing Ability of Elementary School Volleyball. Pedagogia: Jurnal Pendidikan. Vol 8 No 2;157-171

Hermanzony, H. (2020). Pengaruh Kekuatan Otot Lengan dan Daya Ledak Otot Tungkai Terhadap Kemampuan Smash Bolavoli. Jurnal Patriot. Vol 2 No 2; 654-668

Irianto, D. P. (2004). Upaya Meningkatkan Derajat Kebugaran Jasmani dan Kesehatan. Yogyakarta: Lukman offset.

Irwanto, E. (2017). Pengaruh Metode Resiprokal Dan Latihan Drill Terhadap Peningkatan Keterampilan Teknik Dasar Bolavoli. Jurnal Pendidikan Olahraga. Vol 6, No 1; 10-20

Kumar, S., et all. (2016). Effect of Training Program on Volleyball Skills of Inter-University level Volleyball Players. International Journal of Movement Education and Sports Sciences (IJMESS). Vol 4 No 1; $21-25$

Ma'mum, A. \& Subroto, T. (2010). Pendekatan Ketrampilan Taktis Dalam Permainan Bola Voli. Jakarta: Depdiknas.

Sahabudin, S. \& Hakim, H. (2020). Penerapan Latihan Model Dhin Dhon Pada Klub Bolavoli di Kabupaten Bantaeng. Celebes Abdimas. Vol 2 No 1; 33-42

Sarwita, T. (2017). Pengaruh Latihan Passing Bawah Berpasangan Terhadap Ketepatan Passing Bawah Dalam Permainan Bolavoli Pada Klub Pervodac. Jurnal Penjaskesrek, ISSN 2355-0058. Vol 4 No $1 ; 31-37$

Wahyudi, W. \& Donie, D. (2019). Motivasi Berprestasi Atlet Sepakbola Jordus FC Kota Batusangkar. Jurnal Pendidikan dan Olahraga , 2 (1), 126-130.

Winarno, et all. (2013). Teknik Dasar Bermain Bolavoli. Malang: UM Press 